\section{Acute airway obstruction as a complication of untreated achalasia}

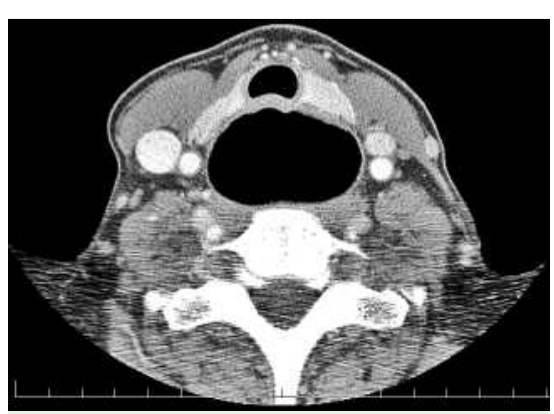

Figure 1 Computed tomographic image showing the cervical esophagus at a level where it was not impinging on the trachea.

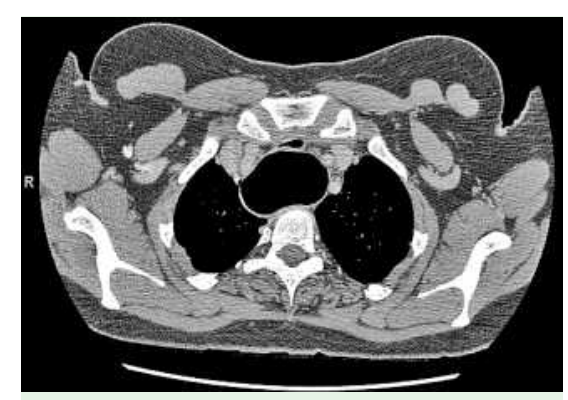

Figure 2 Thoracic computed tomographic image showing severe tracheal compression resulting from a massively dilated esophagus.

A healthy 50-year-old white woman presented to the emergency department with acute-onset stridor and dyspnea. Although she had been diagnosed with achalasia 12 years earlier, she had declined therapy and had experienced minimal dysphagia. On arrival at the hospital, she was found to be cyanotic and bradycardic, and required emergency endotracheal intubation. She was extubated soon afterwards, but required nebulized racemic epinephrine because of persistent expiratory stridor. Computed tomography showed dilatation of the proximal cervical esophagus that did not impinge on the trachea ( $\bullet$ Figure 1 ). However, a more distal computed tomographic slice showed the esophagus to be severely dilated and compressing the posterior wall of the trachea ( $\bullet$ Figure 2 ). Upper endoscopy revealed a dilated esophagus with normal gastric and esophageal mucosa. After dilation of the lower esophageal sphincter with a $20-\mathrm{mm}$ balloon, the patient felt dramatically better, with complete resolution of her stridor. She subsequently underwent an uncomplicated Heller myotomy with Dor fundoplication. Airway obstruction due to achalasia has been reported primarily in women beyond their fifth decade of life. Several mechanisms have been proposed. Early reports suggested that dysfunction of the cricopharyngeal muscle, associated with cephalad movement of a dilated esophagus, causes progressive esophageal dilatation [1]. More recently, a defective upper esophageal sphincter belch reflex has been implicated $[2,3]$. Therapy is first directed at securing the airway. Patients with respiratory failure due to achalasia frequently require endotracheal intubation or emergency esophageal decompression. We recommend that stable patients are cared for in a highly monitored environment with facilities for rapid endotracheal intubation prior to esophageal decompression, as oropharyngeal manipulation can exacerbate a delicate airway situation. Heller's myotomy is the most common long-term decompression strategy, but good results have also been reported with injection of botulinum toxin (Botox) into the lower esophageal sphincter $[4,5]$.

Endoscopy_UCTN_Code_CCL_1AB_2AC_3AD

\section{J. S. Healy, J. Baillie}

Section on Gastroenterology, Wake Forest University Baptist Medical Center,

Winston-Salem, North Carolina, USA

\section{References}

1 McLean RD, Stewart CJ, Whyte DG. Acute thoracic inlet obstruction in achalasia of the oesophagus. Thorax 1976; 31: 456-459

2 Becker DJ, Castell DO. Acute airway obstruction in achalasia: possible role of defective belch reflex. Gastroenterology 1989; 97: 1323- 1326

3 Massey BT, Hogan WJ, Dodds WJ, Dantas RO. Alteration of the upper esophageal sphincter belch reflex in patients with achalasia. Gastroenterology 1992; 103: 1574 - 1579

4 Arcos E, Medina C, Mearin F et al. Achalasia presenting as acute airway obstruction. Dig Dis Sci 2000; 45: 2079-2083

5 Ali GN, Hunt DR, Jorgensen JO et al. Esophageal achalasia and coexistent upper esophageal sphincter relaxation disorder presenting with airway obstruction. Gastroenterology 1995; 109: $1328-1332$

\section{Bibliography}

DOI 10.1055/s-2007-966486

Endoscopy 2007; 39: E222

(c) Georg Thieme Verlag KG Stuttgart · New York . ISSN 0013-726X

\section{Corresponding author \\ J. S. Healy, MD}

Section on Gastroenterology

Medical Center Blvd.

Wake Forest University Baptist Medical Center Winston-Salem

North Carolina 27157

USA

Fax: +1-336-713-7322

joeshealy@gmail.com 